\title{
Épocas de poda e produtividade da mandioca
}

\author{
Eduardo Barreto Aguiar(1), Silvio José Bicudo(1), Felipe Curcelli(1), Priscila Gonzales Figueiredo(1) \\ e Simério Carlos Silva Cruz(2)
}

\begin{abstract}
(1)Universidade Estadual Paulista, Faculdade de Ciências Agronômicas, Caixa Postal 237, CEP $18603-970$ Botucatu, SP. E-mail: aguiareb@msn.com, sjbicudo@fca.unesp.br, felipecurcelli@yahoo.com.br, priscila_figueiredo3@hotmail.com (2)Universidade Estadual de Goiás, Rua São João, s/nº, CEP 76194-970 Palmeiras de Goiás, GO. E-mail: simerio_cruz@hotmail.com
\end{abstract}

Resumo - O objetivo deste trabalho foi avaliar o efeito de diferentes épocas de poda no desenvolvimento, na produção e na qualidade de raízes tuberosas de mandioca. Foram conduzidos dois experimentos, em duas localidades do Estado de São Paulo: Botucatu, em área de solo argiloso, e São Manuel, em solo arenoso. Os experimentos foram conduzidos de setembro de 2008 a junho de 2010 , e a colheita foi feita após dois ciclos vegetativos (22 meses). Utilizou-se o delineamento experimental de blocos ao acaso, com quatro repetições. Foram avaliados dez tratamentos, nove épocas de poda espaçadas mensalmente, entre abril e dezembro, e uma testemunha conduzida sem poda. As épocas de poda foram analisadas estatisticamente por contrastes ortogonais, em comparação à testemunha, e por regressão. A poda da mandioca realizada no período de repouso fisiológico não altera o teor de matéria seca e a produtividade de raízes tuberosas. No entanto, quando realizada no final do primeiro ciclo ou após o início do segundo ciclo vegetativo, a poda reduz o teor de matéria seca e a produtividade de raízes.

Termos para indexação: Manihot esculenta, práticas culturais, repouso fisiológico, teor de matéria seca.

\section{Pruning dates and productivity of cassava}

\begin{abstract}
The objective of this work was to assess different pruning dates on the development, production and quality of cassava roots. Two experiments were carried out in two regions of the state of São Paulo, Brazil: Botucatu, on clay soil, and São Manuel, on sandy soil. The experiments were carried out from September 2008 to June 2010, and harvest was done after two growing seasons (22 months). The experimental design was a randomized block design, with four replicates. Ten treatments, nine monthly pruning dates, between April and December, and a control cultivated without pruning were evaluated. Pruning dates were statistically analyzed by orthogonal contrasts, in comparison to the control, and by regression. Cassava pruning during the rest period does not alter dry matter content and root yield. However, when performed at the end of the first cycle or after the start of the second cycle, pruning reduces dry matter content and root yield.
\end{abstract}

Index terms: Manihot esculenta, cultural practices, rest period, dry matter content.

\section{Introdução}

Por sua tolerância a diversos regimes pluviométricos, a altas temperaturas e a solos de baixa fertilidade, a mandioca (Manihot esculenta Crantz) é cultivada em praticamente todas as regiões de clima tropical do mundo, principalmente nas regiões pouco desenvolvidas e por pequenos agricultores (Howeler, 2002). A mandioca é a terceira fonte de calorias na alimentação humana nos trópicos, depois do arroz e do milho (Food and Agriculture Organization of the United Nations, 2008). No Brasil e em outros países da América Latina, da África e da Ásia, a mandioca também é cultivada para a industrialização.
A principal característica que define a qualidade da produção de raízes de mandioca para a indústria é o teor de matéria seca (Lorenzi, 2003). O teor de matéria seca apresenta correlação direta com o teor de amido (Borges et al., 2002), matéria-prima extraída por fecularias, fábricas de polvilho e indústrias de álcool de mandioca. $\mathrm{O}$ teor de amido corresponde a aproximadamente $85 \%$ do teor de matéria seca das raízes, e, por ser de difícil determinação analítica, em termos práticos, é estimado nas indústrias a partir do teor de matéria seca (Cereda et al., 2003; Carvalho et al., 2007).

A época de colheita da mandioca é bastante ampla e pode variar de 6 a 24 meses, dependendo do uso, da cultivar, do clima da região, dos tratos culturais e 
do mercado consumidor (Albuquerque et al., 2009). Nas regiões brasileiras de clima tropical e temperado, onde ocorrem períodos anuais bem definidos de seca e ou de baixas temperaturas (Instituto Brasileiro de Geografia e Estatística, 2005), a mandioca industrial normalmente é colhida entre 16 e 24 meses, após dois ciclos vegetativos de desenvolvimento (Conceição, 1981; Lorenzi, 2003). A colheita nessa época é altamente vantajosa, pois proporciona substancial aumento na produção de raízes, em comparação à produção obtida em apenas um ciclo vegetativo (Lorenzi, 2003; El-Sharkawy, 2006; Sagrilo et al., 2006). Entre o primeiro e o segundo ciclos vegetativos, a mandioca passa por um período de repouso fisiológico, caracterizado por paralização do crescimento vegetativo, redução da atividade metabólica e desfolha natural das plantas. Esse período ocorre na época mais fria e ou seca do ano (Normanha \& Pereira, 1962; Conceição, 1981; Lorenzi, 2003; El-Sharkawy, 2006).

Parcela significativa do custo de produção da cultura da mandioca pode ser atribuída ao controle das plantas daninhas, que pode variar conforme as espécies daninhas e as suas densidades populacionais, o sistema de plantio e o método de controle. A mandioca é considerada uma cultura de crescimento lento que cobre insuficientemente o solo, o que a torna altamente susceptível à competição com plantas daninhas. Além do uso de herbicidas, a capina manual é uma prática cultural muito utilizada, principalmente em pequenas áreas. O conhecimento do período crítico de interferência das plantas daninhas é fundamental para estabelecer quando iniciar as capinas e qual o número de capinas a serem realizadas (Albuquerque et al., 2008).

$\mathrm{O}$ surgimento de grandes áreas de mandioca para o fornecimento de matéria-prima para a indústria vem exigindo sistemas produtivos cada vez mais eficientes, que permitam à cultura da mandioca melhor competitividade com outras commodities (Aguiar, 2011). A poda da parte aérea da mandioca em grandes áreas é uma prática cultural indispensável para o controle das plantas infestantes com herbicidas, no segundo ciclo, embora os resultados disponíveis na literatura ainda sejam controversos (Takahashi, 1998; Lorenzi, 2003; Peressin, 2010).

Diversos autores relatam que a prática da poda pode causar redução na produção e no teor de amido das raízes (Normanha \& Pereira, 1962; Correia et al., 1973; Oliveira et al., 2010). Outros ainda não observaram diferenças significativas na produção de raízes, em comparação a plantas podadas no período de repouso fisiológico e a testemunhas sem poda (Conceição, 1981; Takahashi, 1998). Andrade (2010), demonstrou que a poda pode proporcionar aumento na produção e no teor de matéria seca das raízes de mandioca.

De acordo com Takahashi (1998) e Lorenzi (2003), os efeitos da poda na produção de raízes de mandioca podem variar, entre outros fatores, em função da época de poda, do clima e da fertilidade do solo, o que justifica, em parte, a dispersão dos resultados observados na literatura.

O objetivo deste trabalho foi avaliar o efeito de diferentes épocas de poda no desenvolvimento, na produção e na qualidade de raízes tuberosas de mandioca.

\section{Material e Métodos}

Dois experimentos similares foram conduzidos nos Municípios de Botucatu e São Manuel, SP. O solo do local de instalação dos experimentos, em Botucatu e São Manuel é classificado como Nitossolo Vermelho distroférrico estruturado, e como Latossolo Vermelho distroférrico típico, respectivamente, (Santos et al., 2006). O clima dos dois locais, segundo a classificação de Köppen, é do tipo Cfa, temperado quente (mesotérmico) úmido (Cunha \& Martins, 2009). A variedade de mandioca cultivada foi a IAC 14, de amplo uso industrial na região Centro-Sul do Brasil. Na Figura 1, estão descritas as temperaturas máximas e mínimas e as precipitações mensais observadas em Botucatu e São Manuel.

Ambos os experimentos foram implantados em setembro de 2008, em blocos ao acaso, com quatro repetições. As parcelas foram formadas por quatro linhas de 12 plantas, com espaçamento de 1,00x0,80 m, o que totalizou 12.500 plantas por hectare. Para as avaliações, foram colhidas 20 plantas das duas linhas centrais de cada parcela, tendo-se descartado as plantas das extremidades das linhas.

O plantio foi realizado com manivas de $20 \mathrm{~cm}$, dispostas nos sulcos de plantio a $10 \mathrm{~cm}$ de profundidade. A adubação nos dois experimentos foi a mesma realizada no sulco de plantio, com $200 \mathrm{~kg} \mathrm{ha}^{-1}$ da fórmula N-P-K (8-28-16) + 0,5\% de Zn, calculada segundo as recomendações para o Estado de São Paulo (Raij et al., 1996), e conforme análise de solo (Tabela 1). 
Foram avaliados, em cada experimento, dez tratamentos: nove épocas de poda e uma testemunha conduzida sem poda. As épocas de poda foram espaçadas mensalmente, de abril a dezembro de 2009, e distribuídas entre o primeiro e o segundo ciclo vegetativo.

O controle das plantas daninhas no primeiro ciclo foi realizado com aplicação de herbicida formulado à base de ametrina + clomazone $\left(300+200 \mathrm{~g} \mathrm{~L}^{-1}\right.$ de i.a. $)$, em pós-plantio, antes da emergência da mandioca. Em dezembro de 2008 e março de 2009, foram realizadas duas capinas manuais. Durante o segundo ciclo e após a poda, o controle das plantas daninhas foi realizado com capinas manuais sempre que necessário. Não houve ocorrência significativa de pragas ou doenças.

A poda da parte aérea foi realizada manualmente, com facão, $10 \mathrm{~cm}$ acima do nível do solo (Lorenzi, 2003). Toda a parte aérea podada foi retirada da área experimental para facilitar os demais tratos culturais.
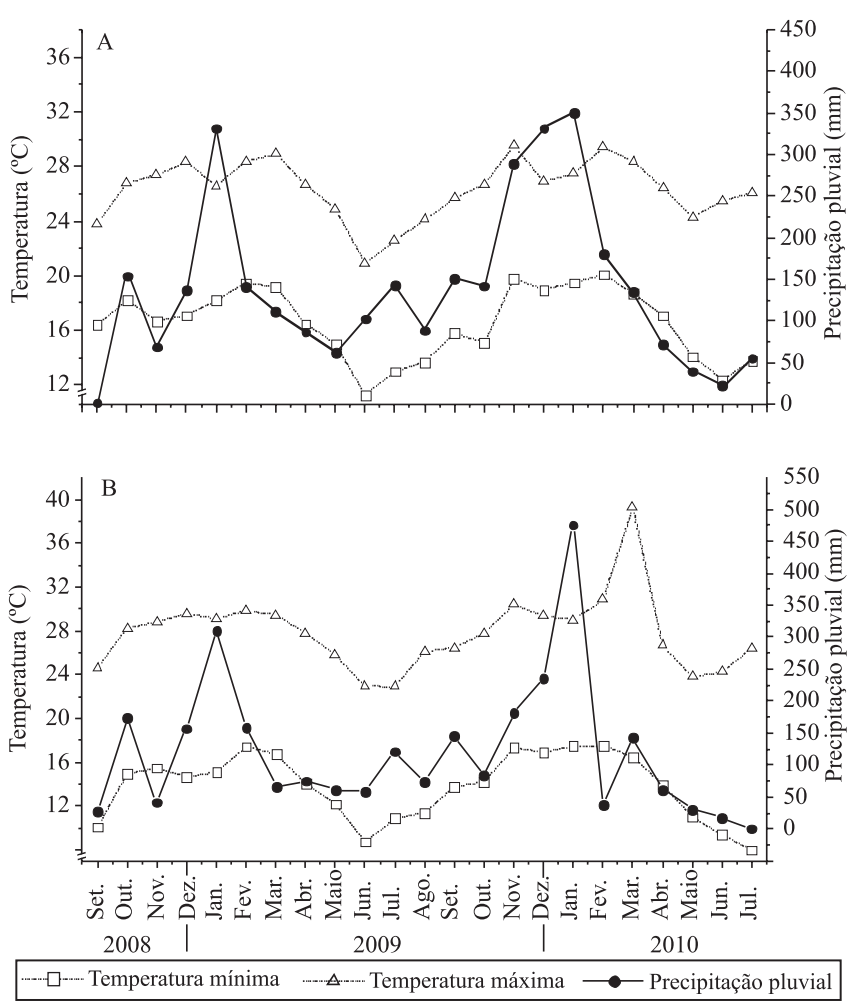

Figura 1. Temperaturas máximas, mínimas e precipitações pluviais mensais observadas de setembro de 2008 a julho de 2010, em Botucatu, SP (A), e em São Manuel, SP (B).
A colheita foi realizada manualmente em junho de 2010, 22 meses após o plantio, após a descompactação do solo com subsolador de mandioca (afofador).

Os parâmetros avaliados foram: número médio de raízes por planta, massa média de matéria seca de raízes (quilogramas por raiz), teor de matéria seca de raízes (percentagem) e produtividade de matéria seca de raízes $\left(\mathrm{Mg} \mathrm{ha}^{-1}\right)$.

O número médio de raízes por planta foi obtido pela divisão do número total de raízes colhidas pelo número de plantas de cada parcela (20 plantas).

Para a determinação do teor de matéria seca das raízes, separaram-se dez raízes, aleatoriamente, em cada parcela, que foram picadas em máquina de raspa de mandioca. Desse montante, foram retiradas amostras homogêneas de aproximadamente $400 \mathrm{~g}$ de peso fresco, que foram secas em estufa com circulação de ar forçado a $60^{\circ} \mathrm{C}$ até peso constante. A partir da diferença entre a massa fresca e seca das amostras, obteve-se o teor de matéria seca (Aguiar, 2011).

A produtividade de matéria seca de raízes $\left(\mathrm{Mg} \mathrm{ha}^{-1}\right)$ foi estimada a partir do teor de matéria seca e da produtividade de raízes frescas por parcela.

A massa média de matéria seca de raízes (quilogramas por raiz) foi determinada pela divisão da massa de

Tabela 1. Analises dos atributos químicos $(0-20 \mathrm{~cm})$ e granulométricos $(20-40 \mathrm{~cm})$ do solo nas áreas experimentais de Botucatu, SP, e São Manuel, SP, em 2008.

\begin{tabular}{lcc}
\hline Atributo & Botucatu & São Manuel \\
\hline $\mathrm{pH} \mathrm{em} \mathrm{CaCl}$ & 5,0 & 6,0 \\
$\mathrm{MO}\left(\mathrm{g} \mathrm{dm}^{-3}\right)$ & 21 & 8 \\
$\mathrm{P}(\mathrm{resina})\left(\mathrm{mg} \mathrm{dm}^{-3}\right)$ & 15 & 22 \\
$\mathrm{Al}^{3+}\left(\mathrm{mmol}_{\mathrm{c}} \mathrm{dm}^{-3}\right)$ & 0 & - \\
$\mathrm{H}+\mathrm{Al}\left(\mathrm{mmol}_{\mathrm{c}} \mathrm{dm}^{-3}\right)$ & 44 & 14 \\
$\mathrm{~K}\left(\mathrm{mmol}_{\mathrm{c}} \mathrm{dm}^{-3}\right)$ & 2,9 & 2,3 \\
$\mathrm{Ca}\left(\mathrm{mmol}_{\mathrm{c}} \mathrm{dm}^{-3}\right)$ & 30 & 24 \\
$\mathrm{Mg}\left(\mathrm{mmol}_{\mathrm{c}} \mathrm{dm}^{-3}\right)$ & 13 & 9 \\
$\mathrm{SB}\left(\mathrm{mmol}_{\mathrm{c}} \mathrm{dm}^{-3}\right)$ & 46 & 35 \\
$\mathrm{CTC}\left(\mathrm{mmol}_{\mathrm{c}} \mathrm{dm}^{-3}\right)$ & 90 & 49 \\
$\mathrm{~V}(\%)$ & 52 & 71 \\
$\mathrm{~B}\left(\mathrm{mg} \mathrm{dm}^{-3}\right)$ & 0,38 & 0,23 \\
$\mathrm{Cu}\left(\mathrm{mg} \mathrm{dm}^{-3}\right)$ & 10,5 & 0,8 \\
$\mathrm{Mn}\left(\mathrm{mg} \mathrm{dm}^{-3}\right)$ & 79,4 & 17,1 \\
$\mathrm{Zn}\left(\mathrm{mg} \mathrm{dm}^{-3}\right)$ & 1,7 & 1 \\
$\mathrm{Fe}\left(\mathrm{mg} \mathrm{dm}^{-3}\right)$ & 16 & 10 \\
Areia $\left(\mathrm{g} \mathrm{kg}^{-1}\right)$ & 217 & 823 \\
$\mathrm{Silte}\left(\mathrm{g} \mathrm{kg}^{-1}\right)$ & 567 & 124 \\
Argila $\left(\mathrm{g} \mathrm{kg}^{-1}\right)$ & 216 & 53 \\
Textura & Argilosa & Arenosa \\
\hline
\end{tabular}


matéria seca de raízes (quilogramas) pelo número de raízes colhidas em cada parcela.

$\mathrm{O}$ efeito de época de poda foi analisado estatisticamente por contrastes ortogonais, em comparação à testemunha sem poda, no total de nove contrastes avaliados em cada local (Nogueira, 2004, 2007), e por análise de regressão (Pimentel-Gomes \& Garcia, 2002).

Os contrastes ortogonais entre as épocas de poda e a testemunha correspondem a variáveis qualitativas. A comparação entre as épocas de poda foi realizada quantitativamente por regressão, o que permite identificar o melhor período para a prática da poda entre as épocas avaliadas (Pimentel-Gomes \& Garcia, 2002; Nogueira, 2007).

Para a análise estatística dos contrastes ortogonais, foi utilizado o programa Statistical Analysis System (SAS 9.0), por meio dos comandos "proc glm" e "contrast" (Nogueira, 2004, 2007). Para as análises de regressão e a determinação dos respectivos coeficientes de determinação $\left(\mathrm{R}^{2}\right)$, foram utilizados os programas Curvexpert 1.4 (Hyams, 2010) e Origin 6.0 (Deschenes \& Vanden, 2000).

\section{Resultados e Discussão}

Nos dois experimentos, as menores temperaturas e precipitações pluviais foram registradas de maio a julho de 2009, quando ocorreu o período de repouso fisiológico (Figura 1).

O número médio de raízes por planta nas diferentes épocas de poda avaliadas não diferiu significativamente da testemunha sem poda, por análise dos contrastes ortogonais, em Botucatu e São Manuel (Tabela 2). Resultados semelhantes foram observados por Takahashi (1998). Pelas análises de regressão não houve efeito significativo entre as épocas de poda e o número de raízes, (Figura 2). Em média, o número de raízes por planta observado em Botucatu foi de 6,93 raízes por planta e, em São Manuel, de 6,35 raízes por planta. O número de raízes por planta é definido até aproximadamente 120 dias após o plantio (Lorenzi, 2003; Alves, 2006), período que antecedeu todas as épocas de poda avaliadas, o que justifica a ausência de efeito no número médio de raízes por planta.

Em São Manuel, as podas realizadas entre setembro e dezembro e em abril, proporcionaram redução da massa média de matéria seca de raízes, em comparação à testemunha (Tabela 2). Em Botucatu, houve redução significativa da massa média de matéria seca de raízes somente para a poda realizada em outubro. As podas realizadas de maio a agosto, em ambos os locais, não alteraram de modo significativo a massa média de matéria seca de raízes. Entre maio e julho, foram observadas as melhores épocas de poda, independentemente do local (Figura 2). As podas realizadas em abril e a partir de agosto provocaram redução na massa média de matéria seca de raízes em Botucatu e São Manuel. Portanto, as melhores épocas de poda foram observadas no período de repouso fisiológico, em concordância com Lorenzi (2003), Andrade (2010) e Peressin (2010).

Com relação ao teor de matéria seca, as podas realizadas a partir de outubro, em Botucatu, e a partir de setembro, em São Manuel, reduziram significativamente os teores de matéria seca das raízes, em comparação à testemunha sem poda (Tabela 3). Pela análise de regressão, para as podas realizadas entre abril e agosto, os teores de matéria seca das raízes mantiveram-se altos e praticamente constantes, com média de 40,90\%, em Botucatu, e de 45,95\% em São Manuel (Figura 3). No entanto, para as podas realizadas a partir do mês de setembro, houve redução nos teores de matéria seca das raízes, para $36,12 \%$, em Botucatu, e para 41,29\%, em São Manuel, com a poda em dezembro.

Tabela 2. Número de raízes por planta e massa de matéria seca de raízes da variedade de mandioca IAC 14 colhida com dois ciclos vegetativos, 22 meses após o plantio, em Botucatu, SP, e São Manuel, SP, com diferentes épocas de poda.

\begin{tabular}{|c|c|c|c|c|}
\hline \multirow[t]{2}{*}{ Época de poda } & \multicolumn{2}{|c|}{$\begin{array}{l}\text { № de raízes } \\
\text { por planta }\end{array}$} & \multicolumn{2}{|c|}{$\begin{array}{l}\text { Massa de matéria seca } \\
\text { de raízes (kg por raiz) }\end{array}$} \\
\hline & Botucatu & São Manuel & Botucatu & São Manuel \\
\hline Abril & $6,83^{\text {ns }}$ & $6,00^{\mathrm{ns}}$ & $0,127^{\mathrm{ns}}$ & $0,231^{*}$ \\
\hline Maio & $7,30^{\mathrm{ns}}$ & $5,40^{\mathrm{ns}}$ & $0,145^{\text {ns }}$ & $0,256^{\text {ns }}$ \\
\hline Junho & $7,18^{\mathrm{ns}}$ & $6,03^{\text {ns }}$ & $0,141^{\text {ns }}$ & $0,268^{\text {ns }}$ \\
\hline Julho & $7,13^{\mathrm{ns}}$ & $5,93^{\mathrm{ns}}$ & $0,152^{\text {ns }}$ & $0,244^{\text {ns }}$ \\
\hline Agosto & $7,45^{\text {ns }}$ & $5,98^{\mathrm{ns}}$ & $0,124^{\mathrm{ns}}$ & $0,277^{\text {ns }}$ \\
\hline Setembro & $6,33^{\text {ns }}$ & $5,88^{\mathrm{ns}}$ & $0,128^{\text {ns }}$ & $0,218^{*}$ \\
\hline Outubro & $7,38^{\mathrm{ns}}$ & $6,58^{\mathrm{ns}}$ & $0,096^{*}$ & $0,195 * *$ \\
\hline Novembro & $7,58^{\text {ns }}$ & $5,90^{\mathrm{ns}}$ & $0,109^{\text {ns }}$ & $0,197 * *$ \\
\hline$\underline{\text { Dezembro }}$ & $5,75^{\text {ns }}$ & $5,40^{\mathrm{ns}}$ & $0,129^{\text {ns }}$ & $0,196^{* *}$ \\
\hline Testemunha (sem poda) & 6,93 & 6,35 & 0,139 & 0,292 \\
\hline $\mathrm{CV}(\%)$ & 16,87 & 18,59 & 21,31 & 17,62 \\
\hline
\end{tabular}


De acordo com diversos autores, a poda pode causar redução nos teores de matéria seca das raízes (Normanha \& Pereira, 1962; Correia et al., 1973; Oliveira et al., 2010). Entretanto, conforme os dados obtidos, variações significativas nos teores de matéria seca das raízes dependem da época em que a poda é realizada. Observou-se redução nos teores de matéria seca das raízes nas podas realizadas a partir de agosto, em decorrência do consumo de carboidratos por novas brotações, no início do segundo ciclo vegetativo, extraídos com a retirada tardia da parte aérea (Normanha \& Pereira, 1962; Conceição 1981; Lorenzi, 2003). Assim, quanto mais tardia for a poda, menor será o período para reposição dessas reservas no segundo ciclo e maior a extração de assimilados das raízes pela
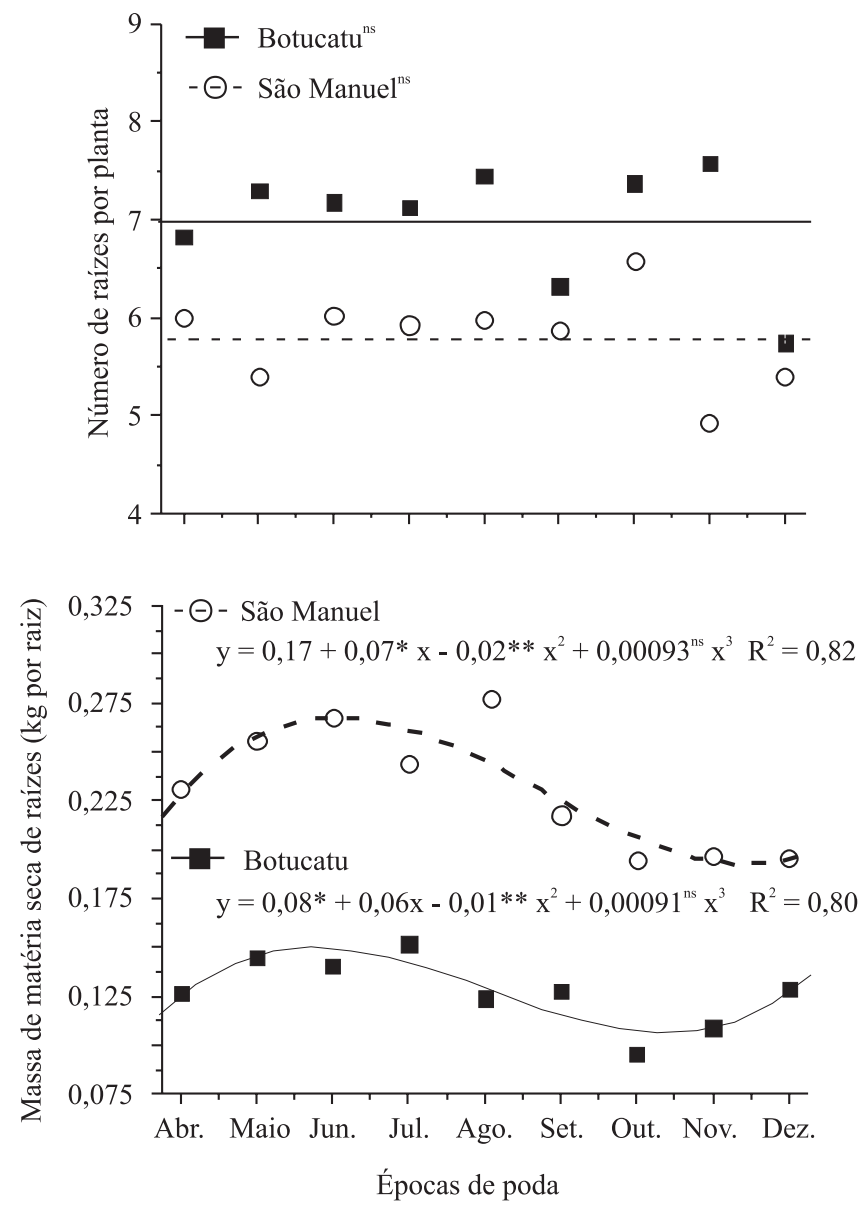

Figura 2. Número de raízes por planta e massa média de matéria seca de raízes, da variedade de mandioca IAC 14, colhida com dois ciclos vegetativos, 22 meses após o plantio, em função das épocas de poda avaliadas em Botucatu, SP, e em São Manuel, SP. retirada da parte aérea, com as novas brotações em pleno desenvolvimento. Os resultados observados no presente trabalho estão de acordo com Andrade (2010), que também observou redução nos teores de matéria seca das raízes com as podas realizadas após o início do segundo ciclo.

Quanto à produtividade de matéria seca de raízes, nos tratamentos em que as podas foram realizadas a partir de setembro, houve redução significativa da produtividade de matéria seca de raízes, em Botucatu e São Manuel (Tabela 3). Observou-se também, em ambos os locais, que a poda realizada em abril reduziu a produtividade de matéria seca de raízes, em comparação à testemunha. Contudo, as podas realizadas no período de repouso fisiológico, entre maio e agosto, em Botucatu, e de junho a agosto, em São Manuel, não alteraram significativamente a produtividade de matéria seca de raízes.

Em Botucatu, a maior estimativa de produtividade de matéria seca de raízes nas podas realizadas de maio a julho foi, em média, de $12,10 \mathrm{Mg} \mathrm{ha}^{-1}$. Em São Manuel, nas podas realizadas de maio a agosto, a média foi de 18,64 $\mathrm{Mg} \mathrm{ha}^{-1}$ (Figura 3). Para as épocas de poda realizadas a partir de setembro, houve redução na produtividade de matéria seca de raízes, que atingiu valores estimados de $8,33 \mathrm{Mg} \mathrm{ha}^{-1}$, em Botucatu, e de $11,67 \mathrm{Mg} \mathrm{ha}^{-1}$ em São Manuel, com a poda em

Tabela 3. Teor e produtividade de matéria seca de raízes da variedade de mandioca IAC 14 colhida com dois ciclos vegetativos, 22 meses após o plantio, em Botucatu, SP, e São Manuel, SP, cultivada com diferentes épocas de poda.

\begin{tabular}{|c|c|c|c|c|}
\hline \multirow[t]{2}{*}{ Época de poda } & \multicolumn{2}{|c|}{ Teor $(\%)$} & \multicolumn{2}{|c|}{ Produtividade $\left(\mathrm{Mg} \mathrm{ha}^{-1}\right)$} \\
\hline & Botucatu & $\overline{\text { São Manuel }}$ & Botucatu & São Manuel \\
\hline Abril & $39,94^{\mathrm{ns}}$ & $46,12^{\text {ns }}$ & $10,37^{*}$ & $17,19^{*}$ \\
\hline Maio & $42,80^{\mathrm{ns}}$ & $45,13^{\mathrm{ns}}$ & $13,16^{\mathrm{ns}}$ & $17,36^{*}$ \\
\hline Junho & $40,93^{\text {ns }}$ & $46,69^{\text {ns }}$ & $12,45^{\mathrm{ns}}$ & $20,04^{\mathrm{ns}}$ \\
\hline Julho & $41,42^{\mathrm{ns}}$ & $46,54^{\mathrm{ns}}$ & $13,17^{\mathrm{ns}}$ & $17,79^{*}$ \\
\hline Agosto & $40,86^{\mathrm{ns}}$ & $46,27^{\mathrm{ns}}$ & $11,48^{\mathrm{ns}}$ & $19,79^{\text {ns }}$ \\
\hline Setembro & $39,50^{\mathrm{ns}}$ & $43,84 *$ & $9,54 * *$ & $16,12 * *$ \\
\hline Outubro & $35,01 * *$ & $43,18 * *$ & $8,74 * *$ & $15,96 * *$ \\
\hline Novembro & $37,11 *$ & $42,98 * *$ & $10,10^{*}$ & $11,75^{* *}$ \\
\hline Dezembro & $37,60 *$ & $41,42 * *$ & $9,28 * *$ & $12,79 * *$ \\
\hline Testemunha (sem poda) & 41,39 & 45,81 & 12,69 & 23,59 \\
\hline $\mathrm{CV}(\%)$ & 6,13 & 2,45 & 14,70 & 22,52 \\
\hline
\end{tabular}

${ }^{n s}$ Médias não diferem significativamente da testemunha pelo método dos contrastes ortogonais. * e $* *$ Médias diferem significativamente da testemunha pelo método dos contrastes ortogonais, a 5 e $1 \%$ de probabilidade, respectivamente. 
dezembro. A poda anterior ao período de repouso fisiológico, realizada em abril, também provocou redução significativa na produtividade de matéria seca de raízes, tendo atingido valores estimados de 11,62 $\mathrm{Mg} \mathrm{ha}^{-1}$, em Botucatu, e de $16,86 \mathrm{Mg} \mathrm{ha}^{-1} \mathrm{em}$ São Manuel.

As maiores produtividades de matéria seca de raízes observadas em Botucatu e em São Manuel, para as podas realizadas no período de repouso fisiológico, estão de acordo com Lorenzi (2003), Andrade (2010) e Peressin (2010), que recomendam a poda como prática cultural nesse período. No entanto, esses resultados discordam de Correia et al. (1973), que observaram redução

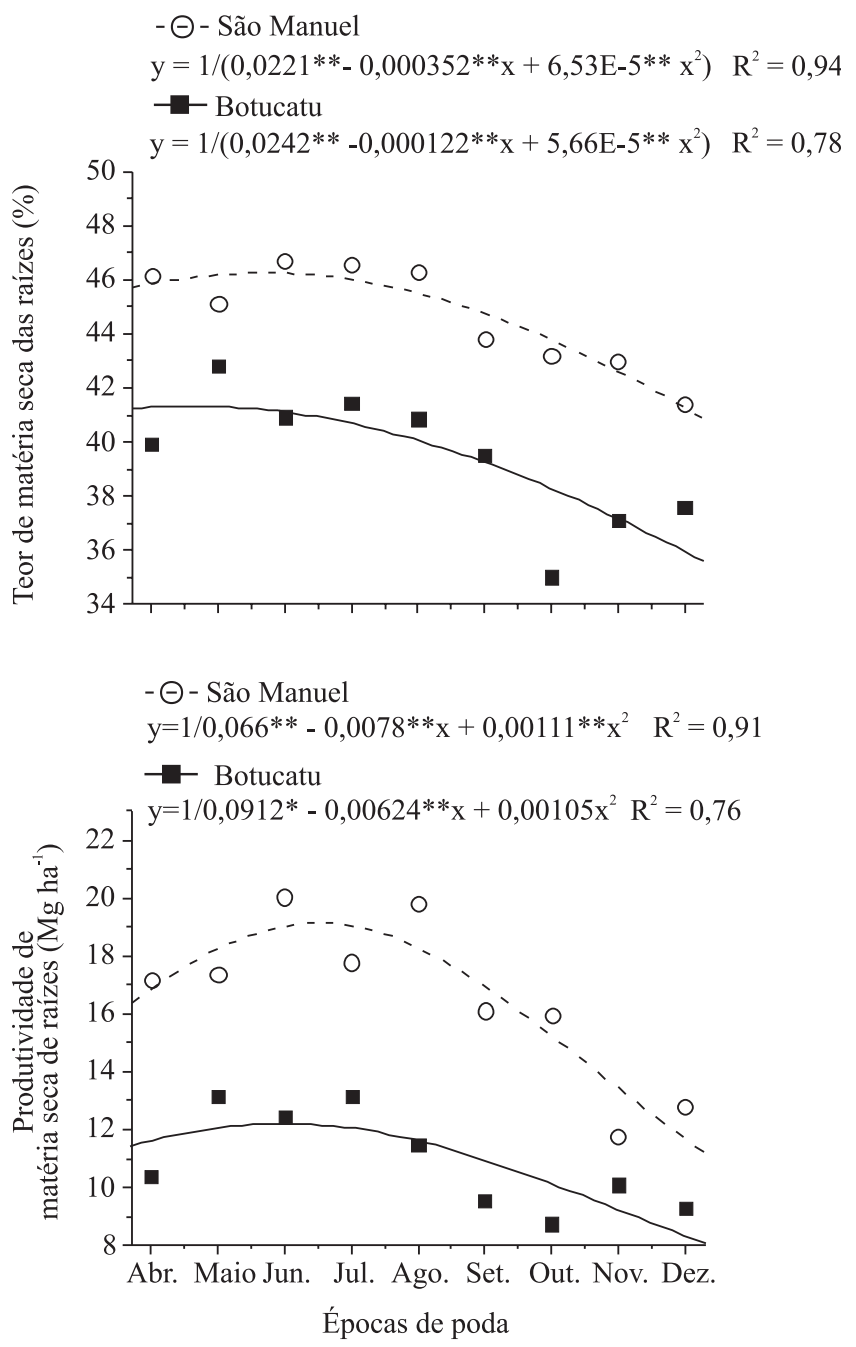

Figura 3. Teor e produtividade de matéria seca de raízes da variedade de mandioca IAC 14 colhida com dois ciclos vegetativos, 22 meses após o plantio, em função das épocas de poda avaliadas em Botucatu, SP, e em São Manuel, SP. na produtividade de raízes com a poda realizada no período de repouso fisiológico, e de Takahashi (1998), que observou redução na produtividade de matéria seca de raízes, no mesmo período, em julho. Os resultados, expressos nas análises de regressão, são indicativos da redução do teor de matéria seca das raízes, com a antecipação da poda em abril e com o atraso a partir de agosto, em ambos os locais (Figura 3 ).

A redução na produtividade de matéria seca de raízes com as podas realizadas a partir de setembro pode ser explicada pela redução na massa média e nos teores de matéria seca de raízes (Tabela 3), bem como pela extração de reservas, mobilizadas das raízes para a parte aérea, com sua retirada após o início das brotações no segundo ciclo vegetativo (Aguiar, 2011). Quanto mais tardia for a poda, maior será a extração, em virtude da mobilização de reservas para as novas brotações, e menor o período de tempo para o desenvolvimento da parte aérea e para o acúmulo de assimilados nas raízes, no segundo ciclo vegetativo. Esses resultados corroboram resultados obtidos por Andrade (2010), que relatou redução na produtividade de raízes com a poda realizada após o período de repouso fisiológico. Assim, a análise de regressão indica que, em ambos os locais, a época ideal para a poda é entre junho e julho, no período de repouso fisiológico, quando se observou maior produtividade de matéria seca e peso médio de raízes.

De acordo com Lorenzi (2003), para o melhor controle das plantas infestantes no segundo ciclo vegetativo, em muitos casos, a poda pode ser retardada para o melhor efeito dos herbicidas. Entretanto, os resultados obtidos em ambos locais, quanto à testemunha sem poda (Tabela 3) e nas análises de regressão (Figura 3), são indicativos de que o atraso da poda pode provocar redução significativa na produtividade e no teor de matéria seca das raízes.

Ao se considerar os efeitos supressivos das plantas daninhas no segundo ciclo vegetativo e que o controle com herbicidas exige, via de regra, a poda do mandiocal (Lorenzi, 2003; Peressin, 2010), conforme os resultados obtidos no presente trabalho, a poda deve ser recomendada no período de repouso fisiológico.

\section{Conclusões}

1. A poda da mandioca realizada no período de repouso fisiológico não altera a massa média, o teor de matéria seca e a produtividade de raízes tuberosas. 
2. A poda da mandioca realizada no final do primeiro ciclo ou após o início do segundo ciclo vegetativo reduz significativamente a massa média, o teor de matéria seca e a produtividade de raízes tuberosas.

3. A poda da mandioca, nas épocas avaliadas, não altera o número médio de raízes por planta.

\section{Agradecimentos}

À Faculdade de Ciências Agronômicas da Universidade Estadual Paulista, pela disponibilização das áreas experimentais, infraestrutura e apoio na realização dos experimentos; à Coordenação de Aperfeiçoamento de Pessoal de Nível Superior, pelo apoio financeiro; e à professora Maria Cristina Stolf Nogueira, da Escola Superior de Agricultura Luiz de Queiroz, da Universidade de São Paulo, pela orientação e pelo auxílio nas análises estatísticas.

\section{Referências}

AGUIAR, E.B. Estudo da poda da mandioca (Manihot esculenta Crantz). 2011. 144p. Tese (Doutorado) - Universidade Estadual Paulista, Botucatu.

ALBUQUERQUE, J.A.A. de; SEDIYAMA, T.; SILVA, A.A. da; CARNEIRO, J.E.S.; CECON, P.R.; ALVES, J.M.A. Interferência de plantas daninhas sobre a produtividade da mandioca (Manihot esculenta). Planta Daninha, v.26, p.279-289, 2008.

ALBUQUERQUE, J.A.A. de; SEDIYAMA, T.; SILVA, A.A. da.; SEDIYAMA, C.S.; ALVES, J.M.A.; ASSIS NETO, F. de. Caracterização morfológica e agronômica de clones de mandioca cultivados no Estado de Roraima. Revista Brasileira de Ciências Agrárias, v.4, p.388-394, 2009.

ALVES, A.A.C. Fisiologia da mandioca. In: SOUZA, L. da S. Aspectos socioeconômicos e agronômicos da mandioca. Cruz das Almas: Embrapa Mandioca e Fruticultura Tropical, 2006. p.138-169.

ANDRADE, J.S. de. Épocas de poda em mandioca. 2010. 62p. Dissertação (Mestrado) - Universidade Estadual do Sudoeste da Bahia, Vitória da Conquista.

BORGES, M. de F.; FUKUDA, W.M.G.; ROSSETTI, A.G. Avaliação de variedades de mandioca para o consumo humano. Pesquisa Agropecuária Brasileira, v.37, p.1559-1565, 2002.

CARVALHO, P.R.N.; MEZZETTE, T.F.; VALLE, T.L.; CARVALHO, C.L.R.; FELTRAN, J.C. Avaliação da exatidão, precisão e robustez do método de análise do teor de matéria seca de mandioca (Manihot esculenta, Crantz) por meio da determinação do peso específico (balança hidrostática). Revista Raízes e Amidos Tropicais, v.3, p.1-4, 2007.

CEREDA, M.P.; VOLPOUX, O.; TAKAHASHI, M. Balança hidrostática como forma de avaliação do teor de massa seca e amido. In: CEREDA, M.P.; VOLPOUX, O. Tecnologia, usos e potencialidade de tuberosas amiláceas latino-americanas. São Paulo: Fundação Cargil, 2003. p.30-47.

CONCEIÇÃO, A.J. da. A mandioca. São Paulo: Nobel, 1981. $382 \mathrm{p}$.

CORREIA, H.; BEZAGO, J.C.E.O.; BRANDÃO, S.S.; GOMES, F.R. Efeito da poda de ramas de mandioca na produção de ramas e raízes. Revista Ceres, v.20, p.148-157, 1973.

CUNHA, A.R. da; MARTINS, D. Classificação climática para os municípios de Botucatu e São Manuel, SP. Irriga, v.14, p.1-11, 2009.

DESCHENES, L.A.; VANDEN, D.A. Origin 6.0: scientific data analysis and graphing software origin lab corporation (formerly Microcal Software, Inc.). Journal of the American Chemical Society, v.122, p.9567-9568, 2000.

EL-SHARKAWY, M.A. International research on cassava photosynthesis, productivity, eco-physiology, and responses to environmental stresses in the tropics. Photosynthetica, v.44, p.481-512, 2006.

FOOD AND AGRICULTURE ORGANIZATION OF THE UNITED NATIONS. Cassava: why cassava? Rome: FAO, 2008. Available at: <http://www.fao.org/ag/agp/agpc/gcds/>. Accessed on: 18 Aug. 2010.

HOWELER, R.H. Cassava mineral nutrition and utilization. In: HILLOCKS, R.J.; THRESH, J.M.; BELLOTTI, A.C. (Ed.). Cassava: biology, production and utilization. Wallingford: CABI, 2002. p.115-147.

HYAMS, D.G. CurveExpert basic. Release 1.4. 2010. Disponível em <http://docs.curveexpert.net/curveexpert/basic/_static/ CurveExpertBasic.pdf $>$. Acesso em: 16 out. 2011.

INSTITUTO BRASILEIRO DE GEOGRAFIA E ESTATÍSTICA. Mapas interativos: mapa de climas. Rio de Janeiro: IBGE, 2005. Disponível em: <http://mapas.ibge.gov.br/clima/viewer.htm>. Acesso em: 24 ago. 2010.

LORENZI, J.O. Mandioca. Campinas: Coordenadoria de Assistência Técnica Integral, 2003. 116p. (CATI. Boletim técnico, 245).

NOGUEIRA, M.C.S. Experimentação agronômica I: conceitos, planejamento e análise estatística. Piracicaba: Maria Cristina Stolf Nogueira, 2007. 479p.

NOGUEIRA, M.C.S. Orthogonal contrasts: definitions and concepts. Scientia Agricola, v.61, p.118-124, 2004.

NORMANHA, E.S.; PEREIRA, A.S. Instruções para a cultura da mandioca. Campinas: Instituto Agronômico, 1962. 28p. (IAC. Boletim, 124).

OLIVEIRA, S.P. de; VIANA, A.E.S.; MATSUMOTO, S.N.; CARDOSO JÚNIOR, N. dos S.; SEDIYAMA, T.; SÃO JOSÉ, A.R. Efeito da poda e de épocas de colheita sobre características agronômicas da mandioca. Acta Scientiarum. Agronomy, v.32, p.99-108, 2010.

PERESSIN, V.A. Manejo integrado de plantas daninhas na cultura da mandioca. Campinas: Instituto Agronômico, 2010. $54 \mathrm{p}$. 
PIMENTEL-GOMES, F.; GARCIA, C.H. Estatística aplicada a experimentos agronômicos e florestais: exposição com exemplos e orientações para uso de aplicativos. Piracicaba: FEALQ, 2002. 309p.

RAIJ, B. van.; CANTARELLA, H.; QUAGGIO, J.A.; FURLANI, A.M.C. (Ed.). Recomendações de adubação e calagem para o Estado de São Paulo. 2.ed. Campinas: Instituto Agronômico, 1996. 285p. (IAC. Boletim técnico, 100).

SAGRILO, E.; VIDIGAL FILHO, P.S.; PEQUENO, M.G.; VIDIGAL, M.C.G.; SCAPIM, C.A.; KVITSCHAL, M.V.; MAIA, R.R.; RIMOLDI, F. Effect of harvest period on foliage production and dry matter distribution in five cassava cultivars during the second plant cycle. Brazilian Archives of Biology and Technology, v.49, p.1007-1018, 2006.

SANTOS, H.G. dos; JACOMINE, P.K.T.; ANJOS, L.H.C. dos; OLIVEIRA, V.A. de; OLIVEIRA, J.B. de; COELHO, M.R.; LUMBRERAS, J.F.; CUNHA, T.J.F. (Ed.). Sistema brasileiro de classificação de solos. 2.ed. Rio de Janeiro: Embrapa Solos, 2006. 306p.

TAKAHASHI, M. Épocas de poda na cultura da mandioca na região noroeste do Paraná, Brasil. Brazilian Archives of Biology and Technology, v.41, p.495-500, 1998.

Recebido em 28 de maio de 2011 e aprovado em 31 de outubro de 2011 